\title{
Intellectual Capital and its Reflection on Quality of Productivity
}

\author{
Aisha Abdalla Al Mahjob Jamal ${ }^{1}$ \\ ${ }^{1}$ Assistant Professor, Department of Human Resources Management, College of Business in $\mathrm{Al}-\mathrm{Kamil}$, \\ University of Jeddah, Saudi Arabia \\ Correspondence: Aisha Abdalla Al Mahjob Jamal, Assistant Professor, Department of Human Resources \\ Management, College of Business in Al-Kamil, University of Jeddah, Saudi Arabia. E-mail: \\ aishajamal82@yahoo.com
}

Received: September 15, 2019

Accepted: October 20, 2019 Online Published: November 8, 2019

doi:10.5539/ijbm.v14n12p67

URL: https://doi.org/10.5539/ijbm.v14n12p67

\begin{abstract}
Intellectual capital is recognized as the primary growth stimulator for an organization. It serves as an instrumental tool for optimizing firms' performance, instigating values in its products, and increasing the quality of its product. This study aims to illustrate the concept and importance of smart capital and its impact on the quality of productivity. The study reviews some of the books and scientists in the area of the intellectual capital model. Previous studies, research papers, journals, and articles are carefully studied to collect useful data. The review revealed a positive relationship between intellectual capital and the quality of productivity. However, greater investments in intellectual capital is required for a higher ratio of firms' productive quality. The given data is significant in establishing the importance of intellectual capital for increasing the quality of productivity and thus, serves as a valuable component in providing greater organizational benefits.
\end{abstract}

Keywords: economy, intellectual capital, knowledge, quality of productivity

\section{Introduction}

Intellectual capital (IC) is recognized as the prime requirement for firms' viability in the competitive globalized environment (Buenechea-Elberdin, 2017; Chen et al., 2010; Kianto, 2011). In management, IC is identified as an intangible asset which the firm holds or has accessibility to. The boom in the IC publications initially emerged in the 1990s, where it was conceptualized to integrate into knowledge and competencies, which help the firm to sustain its competitive edge (Inkinen, 2015). Based on the resource-based organizational view, a sturdy supply of strong intangible assets enables the organization to optimize its performance, gain a competitive edge and innovate (Mention \& Bontis, 2013; Chahal \& Bakshi, 2015; Leitner, 2011; Leitner, 2011). Conventionally, IC constitutes of three components; namely, human capital (HC), structural capital (SC), and relational capital (RC) (Buenechea-Elberdin, 2017). Several studies have emphasized the integration of the three components and their contribution to the overall performance of the firm (Leitner, 2011). Accordingly, the integration of innovation and the IC has been emphasized by several studies that recognize it as a stimulator of improved quality products. The sustainability of any business depends upon the strengthened structure of the intellectual capital (Xu, \& Wang 2019). For various, IC investments are marked as the foremost priority for improving the organizational performance both within the firm as well in the overall markets. Companies that seek to achieve the landmark in market position and financial value mainly focuses on IC and its overall aspects. Planning and implementation of various strategies help in the integration of a successful IC to improve the quality of work. Malkawi (2015) provides a useful explanation, according to which IC represents an elite group of knowledgeable employees, with competent organizational abilities, and can produce new ideas or develop old ideas to seize opportunities.

Alirezaei1 and Paktinat (2017) indicated it as the set of knowledge, competition, experience, intellectual property, along with organizational development and learning that helps to add value to the financial performance of the business. Through intellectual capital, companies tend to instigate greater changes in the organizational performance by employing new working methods through shared knowledge and effective usage of the organizational asset (Fragouli, 2015). Knowledge in this regard has been observed as the primary component of production, which has a major role in creating wealth (Namada, 2018; Abdullah, 2016). The knowledge needs to be transformed and employed so that it is beneficial for individuals involved in the firm's operational activities (Dong et al., 2017). In addition to the intellectual capital along with the strength of intangible resources, the organizational uniqueness tends to improve as well as its cumulative capacity (Jogaratnam, 2017). 
Intellectual capital serves as the prime resource of generating organizational wealth and serves as the major indicator for high-level organizational performance and thus helps in boosting the market value of firms (Gracioli Camfield, Giacomello, \& Sellitto, 2018). Intellectual capital is integrated through effective organizational management, as it forms intangible assets by strengthening human potentials and capabilities through the effective management of intellectual capital to contribute to the quality of productivity. IC management is effective in providing a positive performance outcome in the form of financial stability. It further facilitates firms by providing a competitive value in the business market (Jiang \& Liu 2015). For instance; various Brazilian companies enjoyed a significant increase in the market value due to its high-level intellectual capital (Gracioli Camfield, Giacomello \& Sellitto, 2018). This highlights the value of identifying the intellectual capital and its impact on the quality of productivity within organizations (Alhassan, \& Asare 2016).

The relationship between intellectual capital and the quality of productivity is important in creating an impact on a firm's productivity. This study aims to identify the impact of intellectual capital on improving the quality of a firm's performance. The study focused on different variables of IC that are associated with increasing organizational performance through high-level productivity. Since the study is determined to the objective of providing quality information regarding intellectual capital and its impact on organizational performance, the study holds significant value for various organizational leaders and managers. Besides, the study is further helpful for various organizations as it may guide them to evaluate the existing system of intellectual capital successfully. The information provided in the study includes useful strategies that are beneficial for organizations to improve the quality of productivity at both the internal and external levels.

To draw a holistic picture of the development undergone IC, the review of the existing researches is integral. However, previous researches have empirically investigated the phenomena, where little emphasis is placed on investigating the relationship between IC and production quality. Such as previous studies were either central on the examination of IC, the relationship between IC and innovation, while others on the impact of IC on the organizational performance (Guthrie, Dumay, \& Puntillo, 2015; Ferenhof et al., 2015; Inkinen, 2015). Other researches related to the intellectual capital have been conducted on the general impact of IC on firm performance. Whereas, the analysis of intellectual capital concerning quality productivity is found limited. Thereby, the present study intends to review the articles comprehensively to highlight the relationship of IC with the quality of the production, particularly in the developing and underdeveloped countries. Based on the analysis, the implication and future direction concerning the respective subject is highlighted.

\section{Research Method}

The study has adopted structured literature review method (SLR) as presented by Massaro et al. (2016). The rationale for the selection of this particular design is based on its complementing the conventional literature review approach for deriving different outcomes. Also, this method helps in deriving the fundamental information related to the respective concept while highlighting future directions and implications. Thereby, for the reliable analysis of the intellectual capital for the quality of productivity, SLR serves as an adequate methodology.

\subsection{Review Analysis}

Intellectual Capital comprises of knowledge, experience, and achievements that enable individuals to contribute towards social and organizational development (Abualoush, 2018). Salafah (2017) defines intellectual capital in wider perspectives denoting it as a component that combines in different cognitive and organizational capacities for expanding organization market share, generally concentrated at a certain administrative level. It also highlights that the IC does not require the availability of an academic certificate for progression (Salafah, 2017). Gamayuni (2015) emphasizes the effectual use of intangible assets for optimizing the firm utilization of other physical assets while simultaneously representing the difference between the firm's book value and its market value. When analysing the in-depth concept of intellectual capital, the examination of the following factors is crucial.

\subsubsection{Human Capital}

Employees are recognized as the human capital of an organization. The manpower of an organization is referred to as the backbone of effective organizational performances. The organization tends to lose its human capital when employees intend to leave. Intellectual compatibility, attitude, and individual performance are some major constituents of human capital (Hejazi, Ghanbari, \& Alipour, 2016; Albertini, 2016). Firms provide significant value to strengthen their intellectual capital by hiring more diverse and intellectual employees since the factor is associated with providing effective output in the form of increased productivity and market value. It further serves as the collective output of employees obtained in the form of skills, knowledge, and employees' abilities. 
Various organizations focus on providing training to employees to increase their workability and individual skills that are further used to implement innovative ideas in the organization. The active engagement of employees is thus important to evolve improvements in human capital (Ma et al. 2019). Human capital interacts as a supportive mass of structural capital, which is characterized by change and continuity. Greater interaction among people, greater with be the realization of the value of knowledge capital (Manuti, Impedovo \& De Palma 2017).

\subsubsection{Structural Capital}

Structural capital reflects the type of knowledge that is intervened in the organizational process and everyday work practices. Knowledge in the given category is integrated through outsources, that provides fundamental support to human capital. An upgraded structural capital is formed through the organizational culture, administrative system, organizational process, along with its internal structure (Hejazi, Ghanbari \& Alipour, 2016). Wang et al. (2016) analyzed the effectiveness of intellectual capital and knowledge management and its influence on a firm's performance. Results indicated that effective knowledge management, i.e. (structural capital) is important to increase the financial performance of firms. The structural capital is further divided into two categories, namely; organizational and technological capital (Khaliq \& Isa 2019). The first deals with the implementation of different activities that are incorporated through explicit and implicit assets of the company (Roos, 2017).

\subsubsection{Social Capital}

Social capital refers to the effectiveness of the interpersonal relationships shared within the organization. Social capital is often referred to as the subcategory of human capital. The characteristics that are discussed in human capital are only functional through a group of individuals. The associated personnel are any social group often shares important knowledge and assist each other in complex organizational tasks (Golmoradi, \& Ardabili 2016). However, effective social capital may create a significantly negative impact on organizational performance. Some of these adverse effects include; minimum levels of knowledge sharing, insufficient contribution to organizational innovation, quality of products, inefficient cost of exchange, risk-taking, etc. The role of effective leadership is crucial here, as it can make visible changes in individual and collective attitudes, along with the provision of support to these individuals (Lins, Servaes \& Tamayo 2017). Social capital is further effective when employees provide maximum interest to knowledge capital or the sharing of useful information. The development of organizational knowledge helps in providing more opportunities for organizations to increase resources by involving innovativeness (Kianto, Sáenz \& Aramburu 2017). This helps in the successful development and growth of business in the competitive market.

\section{Relational and Organizational Capital}

Relational capital refers to the implicit conventions of the provided resources along with the relationship developed among individuals through quality interaction (Manes Rossi, Citro \& Bisogno 2016). Whereas, organizational capital mainly involves organizational structure, values, culture and attitudes, information, and other abilities related to telecommunications (Albertini et al., 2016). It further deals with the technical system of an organization that is incorporated through the organizational knowledge leading towards the development of the company (Khalique et al., 2015).

Figure 1 illustrated important characteristics that are often considered in different types of intelligence. Whereas, Figure 2 indicates other important factors that are considered when organizations employ the effective approach of intellectual capital. 


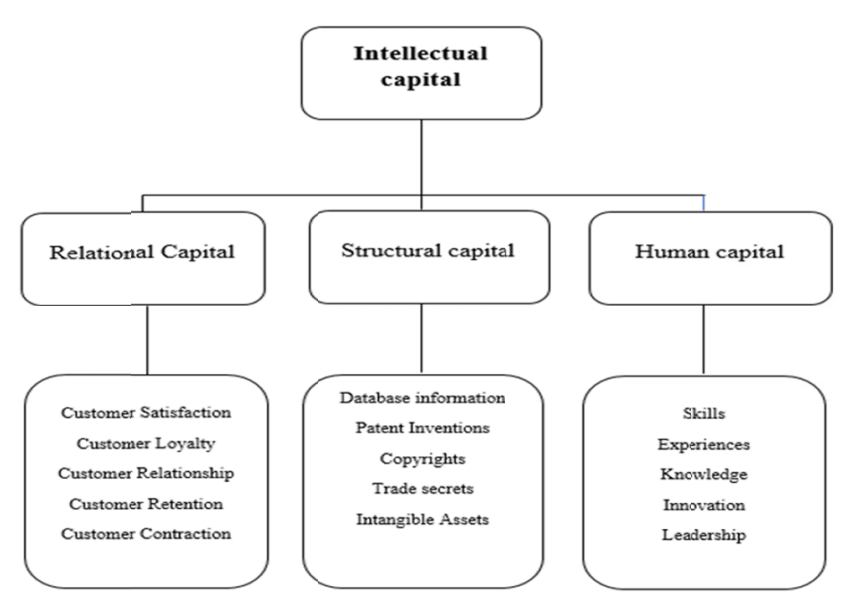

Figure 1. Components of intellectual capital

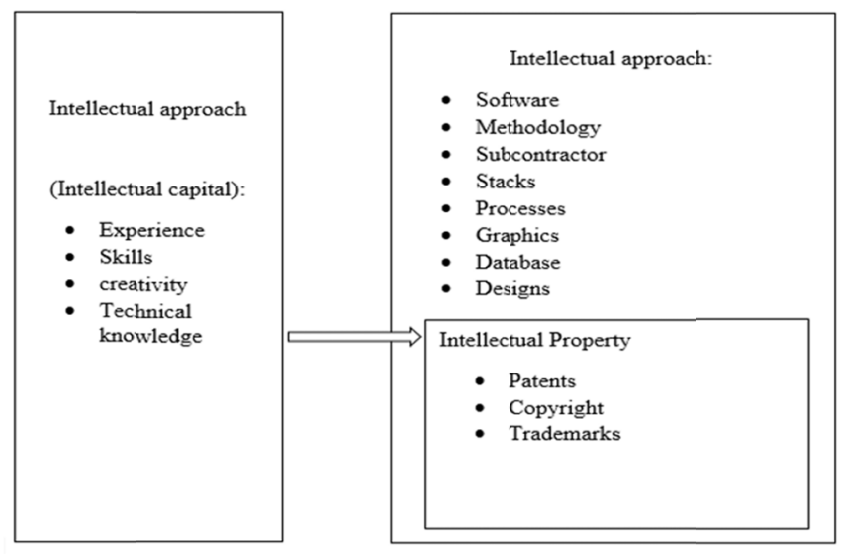

Figure 2. Main components of intellectual capital

\section{Importance of Intellectual Capital in Competitive Businesses}

The importance of intellectual capital is apparent from its contribution to the sustainable development of the company. Intellectual capital is a source of wealth and development for the organization (Herciu \& Ogrean 2015). The intellectual capital is the most valuable asset as it is capable of introducing change in different directions. It is one of the precious resources that are inexhaustible and even tenderer as it provides the means of attention and motivation that make it the most important contributor of national wealth (Hashim, Osman, \& Alhabshi 2015).

On the contrary, complementarity is a central feature of intellectual capital. Human capital components must be available together at a certain level. If a component fails to reach this level, it will be sufficient to prevent other components from being productive (Hassanein, 2016). Alhassan and Asare (2016) analyzed the impact of intellectual capital on the productivity of banks in Africa. Results indicated that intellectual capital, along with the strengthened human capital added significant value to firms' performances through maximum growth, maximum growth, and productivity in the business market. The effectiveness of intellectual capital is provided through an empirical review.

Al-Hadarawi (2015) on the other hand, shed light on the investment in knowledge capital through the training of human resources that commensurate with the actual training needs. The study emphasizes the point that training human resources is an investment in knowledge capital. However, it was analyzed that there is an urgent requirement for training and development programs to enhance skills. Dzenopoljac et al. (2017) further emphasized that human capital, i.e., employee substantially impacted the market performance of the firms in Arab region.

Shawadfi (2017) crystallized the concept of intellectual capital, its various elements, distinguished performance, and methods of measuring it according to the available scientific sources. A significant role is played by standard 
intellectual capital in linking the nature of the various academic performances and the metrics reviewed in the academic performance (Awadallah \& Allam, 2015). Moreover, the characteristics of the dimensions of the work climate and the characteristics of the dimensions of intellectual capital differ from each other. It also showed that there is a significant impact of the dimensions of the work environment on intellectual capital development within the two sectors considering the four dimensions of psychological empowerment including; meaning, efficiency, self-design, and influence (Osman et al., 2016).

Dženopoljac, Janoševic and Bontis (2016) illustrated that intellectual capital follows different important success measures. At first, the value creation of intellectual capital has the potential to manage the future benefit for the organization. Secondly, in the case of Serbian intellectual capital technology, intellectual capital has provided an indirect impact over the company's performance, and help in creating its' value through indirect means. Besides this, different variables of intellectual capital are interlinked with several intangible assets, and thus it is inappropriate to create value on an individual basis. However, Nguyen (2016) emphasized that to properly implement the intellectual capital, as its improper substitution lead towards a limited advantage to the company. Therefore, careful and systematic implementation of intellectual capital is recommended to enjoy the everlasting development and growth of the company. Yaseen, Dajani \& Hasan (2016) further declared it as an important source of providing greater advantages to the organization, as without implementing intellectual capital organizations will not be able to enjoy greater benefits. Similarly, in the case of the Serbian ICT industry, intellectual capital served as an important source of creating value in the existing age of information.

Asiaei and Jusoh (2015) suggested that in various Iranian organizations, intellectual culture plays a crucial role in providing greater benefits to organizational performances. Major focus was provided to structural and human capital in the given framework. Intellectual capital serves as the major driver in providing maximum economic growth to Iranian companies. The idea, however, was incorporated by strengthening the organizational culture and leadership skills. The given variables of intellectual capital have thus provided greater results in terms of improved organizational performances.

Andreeva and Garanina (2016), on the other hand, illustrated the role of intellectual capital in various Russian companies. Intellectual capital is being followed in various organizations of Russia, as an important contributor in providing quality products to the company. Human and Structural capital were the central variables in most of the Russian companies. Through in-depth analysis, it was found that both variables are significant in creating value to organizational performance. It further illustrated that in various Russian industries, despite providing significant value to relational capital, it has not provided greater results.

Organizations are interested in intellectual capital to increase creative capacity, to attract customers, enhance their loyalty, reduce the period between each innovation, and enhance time competition by offering more new or improved products followed by cost reduction and competitive selling (Hamoud et al. 2016). Knowledge possesses a competitive advantage as it has an impact on organizations that deal with ideas, relationships, and communications, especially for financial and advisory organizations. Successful organizations tend to evaluate and implement successful strategies that may provide competitive results through intellectual capital (Abdullah, 2016).

\subsection{Measuring Intellectual Capital}

The evaluation of intellectual capital is done at the level of the organization and the groups with the aim of comparing the current intellectual capital with the needs of future knowledge. The measurement of intellectual capital is established to demonstrate that knowledge as the base of the organization is constantly growing, especially the elements of intellectual capital (human-structural-customer) (Bejinaru, 2016). It mainly emphasizes on how knowledge is converted into goods and services that make it viable and competitive in the future by allocating the resources necessary to achieve growth and maintain knowledge. The aim is to generate new knowledge and strengthen the existing tactical level. The inability to identify and apply knowledge to meet existing needs is a lost opportunity (Arqawi et al., 2018). At the strategic level, moving away from the right knowledge can expose organizations to risk and loss of competitiveness and hence their viability.

Similarly, organizations should not retain intellectual or material assets that are no longer generating added value because it may become an excessive cost borne by organizations (Yassine, 2016). Three components of intellectual capital, i.e., human capital, structural capital, and relational capital depicted that the level of availability of the dimensions of psychological empowerment in the directorate is high (Shawadfi, 2017). The degree of availability of intellectual capital components is also medium, with a statistically significant impact on the psychological ability of the components of intellectual capital. 
The concept of investment in intellectual capital and the role of investment in intellectual capital to achieve the outstanding performance of business organizations has been highlighted by Makid (2016). The study has identified the main components of investment in intellectual capital, along with its outstanding performance. It also determined the importance of building and developing intellectual capital, the relationship between the main components of investment in intellectual capital, and its role in achieving outstanding performance within the economic institutions. The basic elements that relate to employees, management, and customers include human and structural capital. There is a growing interest in economic institutions to invest in intellectual capital to reach the achievement of outstanding performance (Ahmed, Khurshid \& Yousaf 2019). The results depicted the statistically significant relationship between investing in intellectual capital and achieving outstanding performance within the economic institutions. Also, the given variables provide important knowledge regarding the successful analysis of intellectual capital in any organization.

Besides this, intellectual capital plays an important role in achieving the added value of various institutes because it possesses the abilities and advantages that qualify it. There is a defect in the role of human capital in achieving the added value of Saudi institutions. Lack of communication between departments has served a major barrier in the development of effective intellectual capital. The impact of intellectual capital has been studied to enhance the competitive capabilities of students that result in the enhancement of university competitiveness. This determines that institutional capital is not only the need of business firms; rather, it serves as the major contributor to success for the organization.

These methods are used by the organization to revitalize the process of creativity and innovation among workers constantly. The ideas are brainstormed by the people to create their creativity and generate the largest number of ideas at the cost of creating passionate groups that achieve high achievement in work.

\subsection{Intellectual Capital Management}

In innovative companies, knowledge about innovation in the narrow sense creates transformation in new technologies, products, or services (Kulikova et al., 2016). In other companies, they are about leveraging these assets for multiple uses in multiple projects or fields (Fathi \& Ghandour, 2011). Knowledge management is supported through the investment of intellectual capital, provision of flexible, and fast access to information resources and knowledge markets on the Internet (Jam, 2016; Al-Nasser, 2015). Knowledge capital is the product of the interaction of the components together; where, human capital positively affects structural capital, since it is the source of innovation and modernization strategy.

Moreover, the construction of structural capital is the result of human creativity (Delgado-Verde, Martín-de Castro \& Amores-Salvadó 2016). Bezar (2017) identified the role of SWOT (Strength, Vulnerability, Opportunities, and Threats) in the analysis of intellectual capital within the educational organizations. The study has identified the most important factors that affect the intellectual capital within educational organizations, help educational organizations to identify the most important opportunities for developing their intellectual capital, and recognize the most important threats that they may face. For a successful intellectual capital, the organization focuses on identifying and strengthening the strengths of its resources.

They further focus on highlighting the major threats that could impede the development of its resources. Human capital has been observed as one of the core components of the organization's intellectual capital that confirms that the client's capital is an important component of the organization's intellectual capital. Structural capital is the complementary part of the previous components of intellectual capital in the organization. Most of the respondents' answers to the importance of using the SWOT tool in the analysis of capital and intellectual capital were confirmed with positive and significant relationships. Therefore, the SWOT tool has a significant impact on the analysis of the organization's intellectual capital in its four dimensions. Thus, the negative intellectual capital is the result of the failure of a business, as the resources are all gone, and there is nothing left of them.

Khaza'aleh (2017) aimed to provide a theoretical and practical framework to understand the concept of intellectual capital, its components, and important indicators of its measurement and difficulties. The measurement of intellectual capital through the use of several financial instruments are compatible with the available data and information announced by banks through their financial statements (budget and income statement). The study contributed to achieving the most competitive advantage that imposes positivity on its performance. The composition of the intellectual capital components depends on the nature of the banks' work, which is characterized by continuous renewal in the provision of services.

The study conducted by Fengsh (2017) aimed to ascertain the relationship between the intellectual capital represented by its components and the competitive advantage. The availability of intellectual capital components in Sudanese banks was identified by Louisa (2016) to find out if there is a difference in the components of 
intellectual capital to achieve a competitive advantage. The study showed that there is a statistical relationship between the components of intellectual capital (human and customer) and achieving a competitive advantage in the field of superior efficiency.

\subsection{Improving the Quality of Productivity through Intellectual Capital}

There is no general agreement on the concept of quality as it is a broad concept based on different interests and perspectives. Quality is defined through five approaches, including Product Excellence, Distinguished Features, Customer Desire, Compliance with Specification, and Added Value (Sarhan, 2014). It is the ability to achieve the desires of the consumer or the beneficiary in accordance with his expectations and satisfaction with the product or service (Shuaib, 2014). The degree of satisfaction in terms of organizational performance and values determine its quality of productivity. Quality of productivity is the measure of the efficiency and effectiveness of the human element and the effort exerted by the worker to achieve good production and resources to reach the desired goals at specific times and in specific quantities by the ratio of outputs to inputs. The concept of multi-factor quality of productivity is a composite measure of the effectiveness and efficiency of the company (Massy \& Archer 2018).

The reflection and impact of intellectual capital on the quality of productivity are determined by the correlation between the content of each concept (Alhassan \& Asare 2016). It is the skill set available in an organization that has a broad knowledge that makes it able to respond to the requirements of customers and the opportunities offered by technology (Madhavaram \& Hunt, 2017). Technical knowledge, relationships, and machines that embody them have been used to create wealth (Wang \& Wang, 2016). It is the sum of everything that each one in the organization knows and helps them in achieving a competitive advantage in the market (Hassan, 2005). Several studies have highlighted that IC prioritization among the companies vary, i.e., for some the human and structural capital may be prioritized while for some it may be to improve value creation activities through relational capital (Amin et al., 2018; Castro et al., 2013; González-Loureiro \& Dorrego, 2012; Hormiga, Batista-Canino, \& Sánchez-Medina, 2011).

The technological advancement has increased the efficiency of quality of productivity, while simultaneously introducing new methods of production, leading to an increase in engineering and technical staff. The increasing trend of research and design in the total production process has become the most revolutionary element to increase production. The process provides a base for introducing new processes and products (Al-Tikriti, 2010). On the other hand, the concept of quality of productivity is the participation of collective teams, in which each individual has excess capacity. Quality of productivity is improved at a low cost by investing in talent and mental abilities. It helps in the development of collective operation and participatory work to raise the level of quality of productivity. It is a process of investment to invest in efforts towards the increased quality of productivity (Hamdan, 2017).

Enhancing the quality of human capital is essential as one of the primary sources of quality of productivity growth is technological readiness and innovation, which in turn requires a well-organized and skilled workforce (ILO, 2006). In the context of international competition, production is no longer based on traditional production elements to keep pace with progress and growth; rather, it is enhanced by knowledge. Today, the workers in the establishment are considered to be a group of assets and have different ideas for innovations (Mahboob and Abdul, 2016).

New functions have emerged with the spread of e-governance that requires the formation of a synergy relationship with intellectual capital and knowledge management resources through the formation of the real value chain. This helps the organization to achieve a competitive advantage by using networks of suppliers and customers (Hamoud et al. 2016). The quality of productivity of intellectual capital is determined by the multiplication relationship of all its components, provided that the investor has the quantities and qualities that exceed the number specified by the organization (Yassine, 2016). Several studies also emphasize that IC and knowledge management have a significant impact on the innovative performance of the firm (Leitner, 2011; Inkinen, 2015).

The human capital components are not tangible and invisible, which makes it difficult to display, describe, and categorize them. Knowledge management is also supported through the investment of intellectual capital and the provision of flexible providing fast access to information resources and knowledge markets on the Internet. Electronic business systems also contribute to knowledge management activities, especially activities to attract, share, store, disseminate, and create new knowledge (Hamoud et al. 2016). Wei, Liu, \& Herndon (2011) state that for optimizing the use of IC in enhancing the productive quality, the managers must realize their role for eradicating ambiguity towards a goal, providing support to the project, aligning culture and structure while also instigating innovativeness. Camelo-Ordaz et al. (2011) write that IC enables knowledge sharing activity which enhances employee commitment, his input as well as knowledge sharing activity, each contributing to improved performance of the company. 
Quality of productivity is influenced by the morale of workers, and social dimensions affect the quality of productivity (ILO, 2015). The human element is one of the most important elements of production; whereas, the existence of the surplus is an added cost of production and refers to economic waste. This aspect affects the level of welfare and services provided by the state, including the workforce; therefore, the diagnosis of the surplus labor force is considered as a major factor in improving production (Abdel Rahman, 2011). Moreover, informal groups of organizations negatively or positively affect the organization in the interest of the community as a whole (Al-Sharqawi, 2016).

\section{Conclusions}

The literature review on the IC and quality of productivity has highlighted that the integration of the IC escalates the organizational performance. Initially, it observed that IC integrates and combines different units in an organization improving performance. Such as it enables productive quality by combining the individual knowledge, structural arrangement as well as the valuable relationship with each other. The review highlights that firm in order to gain sustainable success, needs to constantly update its knowledge acquisition policy and use for acquiring and increasing interactivity for improved performance. Intellectual capital helps in transforming environmental knowledge and its accurate use. It is because of individual exposure, knowledge, and experience assists in gaining new information while also disseminating it within the firm. This helps increase organizational capabilities enabling transformation and creation of knowledge. To direct the created knowledge in the right direction, including in regulatory mechanism and constantly updating is critical.

The review highlights that the integrated use of the IC helps in the value creation of the firm. It facilitates organization use of resources to determine which resource to use, how to use, and why to use it. It also helps in understanding its relevance to other components of IC. The review recommends that managers must strive for developing and managing the organization using the different IC components. It is likely to assists the managers in identifying how to nurture a firm's organizational capital and manage it effectively. This is likely to assist in devising improved strategies, processes as well as procedures for effectively managing the intellectual capital. The interconnectivity of IC with operational as well as financial performance necessitates that investment must be made on employee selection and recruitment, their training, development as well as procedural design optimization. IC understanding further helps the manager to identify the different effects on the firm. Particularly, the productive quality of the organization emphasizes improving the structural, as well as relational capital. Also, if the aim is to enhance financial performance, then relational capital development should be prioritized.

Similarly, if the emphasis is on the development of human capital, then HR policies and practices must be central for improving the product quality. In case it is not the focal point, then structural and relational policies should be strengthened. Managers are also recommended to use IC for optimizing the innovative potential and improving its competitive edge in the market. Different units of the organization such as R\&D, human resource department, production, and more are suggested to collectively work for driving innovation and quality and synergizing the firm's overall performance. Development of useful plans and strategies may be impactful for the construction and measurement, and investment of intellectual capital. For future researchers, it is suggested to conduct a cross-sectional study, focusing on the major variables of intellectual capital.

\section{Acknowledgments}

The author is highly thankful for all the associated personnel that help in the completion of the research. The study holds no conflicts of interest and is not funded through any source.

\section{References}

Abdel, R. B. (2011). Production Management in Service and Industrial Establishments Analytical Entrance. Dar Al Yazuri Scientific Publishing and Distribution, Amman 210.

Abdullah, M. (2016). The Knowledge Economy. Dar Al Jandariyah Publishing and Distribution, Amman, Jordan.

Abualoush, S., Masa'deh, R. E., Bataineh, K., \& Alrowwad, A. (2018). The role of knowledge management process and intellectual capital as intermediary variables between knowledge management infrastructure and organization performance. Interdisciplinary Journal of Information, Knowledge, and Management, 13, 279-309.

Ahmed, A., Khurshid, M. K., \& Yousaf, M. U. (2019). Impact of Intellectual Capital on Firm Value: The Moderating Role of Managerial Ownership. https://doi.org/10.20944/preprints201901.0318.v1

Albertini, E. (2016). An inductive typology of the interrelations between different components of intellectual 
capital. Management Decision, 54(4), 887-901. https://doi.org/10.1108/md-09-2015-0425

Al-Hadarawi, H. M. (2015). Enhancing investment in knowledge capital according to training needs of human resources in the organization applied study in the reconstruction of Najaf province.

Alhassan, A. L., \& Asare, N. (2016). Intellectual capital and bank productivity in emerging markets: evidence from Ghana. Management Decision, 54(3), 589-609.

Alirezaeil, A. and Paktinat, I. (2017). The Relationship between Social Capital and Intellectual Capital with Staff Productivity (Case Study: Kerman University of Medical Sciences). International Journal of Advanced Biological and Biomedical Research, 5(2), 85-91

Al-Nasser, A. A. R. (2015). Knowledge Management in Business Intelligence Systems. Dar Al-Yazouri Scientific Publishing and Distribution, Amman, Jordan. 43-44.

Al-Sharqawi, I. M. (2016). Business Management from an Economic Perspective. Ghaida Publishers and Publishing House, Amman, Jordan.

Al-Tikriti, H. A. Y. (2010). Mechanisms of Economic Globalization and its Future Implications in the Arab Economy. Dar Al-Hamed Publishing, Amman.

Al-Zubaidi, G. D. T. (2017) Analyzing the Dimensions of Intellectual Capital in Educational Institutions using SWOT Technology. Babylon University of Applied and Applied Sciences, 25(1).

Amin, S., Usman, M., Sohail, N., \& Aslam, S. (2018). Relationship between intellectual capital and financial performance: The moderating role of knowledge assets. Pakistan Journal of Commerce and Social Sciences (PJCSS), 12(2), 521-547.

Andreeva, T., \& Garanina, T. (2016). Do all elements of intellectual capital matter for organizational performance? Evidence from Russian context. Journal of Intellectual Capital, 17(2), 397-412.

Arqawi, S. M., Al Hila, A. A., Abu-Naser, S. S., \& Al Shobaki, M. J. (2018). Obstacles to the Application of Knowledge Management from the Point of View of the Employees at the Technical University of Palestine (Kadoorei).

Asiaei, K., \& Jusoh, R. (2015). A multidimensional view of intellectual capital: the impact on organizational performance. Management Decision, 53(3), 668-697.

Awadallah, E. A., \& Allam, A. (2015). A critique of the balanced scorecard as a performance measurement tool. International Journal of Business and Social Science, 6(7), 91-99.

Bejinaru, R. (2016). Knowledge dynamics impact on intellectual capital in organizations. Management Dynamics in the Knowledge Economy, 4(4), 515-534.

Bezar, A. M. (2017). The role of investment in intellectual capital in achieving the outstanding performance of business organizations. Mohammed Boudiaf University, 2017.

Buenechea-Elberdin, M. (2017). Structured literature review about intellectual capital and innovation. Journal of Intellectual capital, 18(2), 262-285.

Camelo-Ordaz, C., Garcia-Cruz, J., Sousa-Ginel, E., \& Valle-Cabrera, R. (2011). The influence of human resource management on knowledge sharing and innovation in Spain: the mediating role of affective commitment. The International Journal of Human Resource Management, 22(07), 1442-1463.

Castro, G. M. D., Delgado-Verde, M., Amores-Salvadó, J., \& Navas-López, J. E. (2013). Linking human, technological, and relational assets to technological innovation: exploring a new approach. Knowledge Management Research \& Practice, 11(2), 123-132.

Chen, C. J., Huang, J. W., \& Hsiao, Y. C. (2010). Knowledge management and innovativeness: The role of organizational climate and structure. International Journal of Manpower, 31(8), 848-870.

Delgado-Verde, M., Martín-de Castro, G., \& Amores-Salvadó, J. (2016). Intellectual capital and radical innovation: Exploring the quadratic effects in technology-based manufacturing firms. Technovation, 54, 35-47. https://doi.org/10.1016/j.technovation.2016.02.002

Dong, Y., Bartol, K. M., Zhang, Z. X., \& Li, C. (2017). Enhancing employee creativity via individual skill development and team knowledge sharing: Influences of dual-focused transformational leadership. Journal of Organizational Behavior, 38(3), 439-458. https://doi.org/10.1002/job.2134

Dženopoljac, V., Janoševic, S., \& Bontis, N. (2016). Intellectual capital and financial performance in the Serbian 
ICT industry. Journal of Intellectual Capital, 17(2), 373-396. https://doi.org/10.1108/jic-07-2015-0068

Dzenopoljac, V., Yaacoub, C., Elkanj, N., \& Bontis, N. (2017). Impact of intellectual capital on corporate performance: evidence from the Arab region. Journal of Intellectual Capital, 18(4), 884-903.

Fathi, M. and Ghandour, A. H. (2011). Measurements of Information and Knowledge between Theory and Practice. The Egyptian Lebanese Publishing House, 181.

Fengsh, A. L. (2017). The Role of Intellectual Capital in the Financial Performance of Banks. University of Qadisiya, Jordan.

Ferenhof, H. A., Durst, S., Zaniboni Bialecki, M., \& Selig, P. M. (2015). Intellectual capital dimensions: state of the art in 2014. Journal of Intellectual Capital, 16(1), 58-100.

Fragouli, E. (2015). Intellectual Capital \& Organizational Advantage: An economic approach to its valuation and measurement. International Journal of Information, Business and Management, 7(1), 36.

Gamayuni, R. R. (2015). The effect of intangible asset, financial performance and financial policies on the firm value. International journal of scientific \& technology research, 4(1), 202-212.

Golmoradi, R., \& Ardabili, F. S. (2016). The effects of social capital and leadership styles on organizational learning. Procedia-Social and Behavioral Sciences, 230, 372-378.

González-Loureiro, M., \& Dorrego, P. F. (2012). Intellectual capital and system of innovation: What really matters at innovative SMEs. Intangible Capital, 8(2), 239-274.

Gracioli Camfield, C., Giacomello, C. P., \& Sellitto, M. A. (2018). The impact of intellectual capital on performance in Brazilian companies. Journal of technology management \& innovation, 13(2), 23-32. https://doi.org/10.4067/s0718-27242018000200023

Guthrie, J., Dumay, J., \& Puntillo, P. (2015). IC and public sector: a structured literature review. Journal of Intellectual Capital.

Hamdan, K. (2017). Total Quality Management.

Hamoud. A. A, Saad, A. and Ahmed, A. S. (2016). Management of Intellectual Capital in Business Organizations. Dar Kuttab Publishing and Distribution, UAE.

Hashem, N. A. (2016). Intellectual Capital to Achieve the Added Value of Saudi Universities: An Analytical Study. Journal of the Faculty of Education in Educational Sciences, 40(3).

Hashim, M. J., Osman, I., \& Alhabshi, S. M. (2015). Effect of intellectual capital on organizational performance. Procedia-Social and Behavioral Sciences, 211, 207-214.

Hassan. R. (2005). Strategic Approach to Planning and Development of Human Resources. University House, Cairo.

Hassanein, A. J. (2016). Strategic Training. Dar Kuttab Publishing and Distribution, UAE.

Hejazi, R., Ghanbari, M., \& Alipour, M. (2016). Intellectual, human and structural capital effects on firm performance as measured by Tobin's Q. Knowledge and Process Management, 23(4), 259-273. https://doi.org/10.1002/kpm.1529

Herciu, M., \& Ogrean, C. (2015). Wealth, competitiveness, and intellectual capital-sources for economic $\begin{array}{lllll}\text { development. Procedia Economics and } & \text { Finance, }\end{array}$ https://doi.org/10.1016/s2212-5671(15)01033-3

Hormiga, E., Batista-Canino, R. M., \& Sánchez-Medina, A. (2011). The role of intellectual capital in the success of new ventures. International Entrepreneurship and Management Journal, 7(1), 71-92.

ILO. (2006). Achieving Decent Work in Asia, Busan Korea, Asian Regional Meeting, 14.

ILO. (2015). Management Consultancy. Professional Guide. Amman, Jordan.

Inkinen, H. (2015). Review of empirical research on intellectual capital and firm performance. Journal of Intellectual Capital, 16(3), 518-565.

Jam, A. N. (2016). Management of the Non-Management of Immortality. Dar Al-Yazoori Publishing, Amman, Jordan.

Jiang, J. Y., \& Liu, C. W. (2015). High performance work systems and organizational effectiveness: The mediating role of social capital. Human Resource Management Review, 25(1), 126-137. 
https://doi.org/10.1016/j.hrmr.2014.09.001

Jogaratnam, G. (2017). The effect of market orientation, entrepreneurial orientation and human capital on positional advantage: Evidence from the restaurant industry. International Journal of Hospitality Management, 60, 104-113. https://doi.org/10.1016/j.ijhm.2016.10.002

Khalique, M., \& Isa, A. H. M. (2019). Impact of intellectual capital on the organizational performance of airline industry in Malaysia. In Human Performance Technology: Concepts, Methodologies, Tools, and Applications (pp. 1336-1349). IGI Global. https://doi.org/10.4018/978-1-5225-8356-1.ch065

Khalique, M., Bontis, N., Abdul Nassir bin Shaari, J., \& Hassan Md. Isa, A. (2015). Intellectual capital in small and medium enterprises in Pakistan. Journal of Intellectual Capital, 16(1), 224-238. https://doi.org/10.1108/jic-01-2014-0014

Khaza'aleh, A. J. S. (2017). The Impact of Intellectual Capital on Enhancing Competitiveness: A Case Study of Al-Bayt University. Al-Bayt University Business School.

Kianto, A. (2011). The influence of knowledge management on continuous innovation. International Journal of Technology Management, 55(1/2), 110-121.

Kianto, A., Sáenz, J., \& Aramburu, N. (2017). Knowledge-based human resource management practices, intellectual capital and innovation. Journal of Business Research, 81, 11-20. https://doi.org/10.1016/j.jbusres.2017.07.018

Kulikova, N. N., Kolomyts, O. N., Litvinenko, I. L., Gurieva, L. K., \& Kamberdiyeva, S. S. (2016). Features of formation and development of innovation centers generate. International Journal of Economics and Financial Issues, 6(1S), 74-80. https://doi.org/10.1109/ifost.2016.7884256

Leitner, K. H. (2011). The effect of intellectual capital on product innovativeness in SMEs. International Journal of Technology Management, 53(1), 1-18.

Lerro, A., Linzalone, R., Schiuma, G., Kianto, A., Ritala, P., Spender, J. C., \& Vanhala, M. (2014). The interaction of intellectual capital assets and knowledge management practices in organizational value creation. Journal of Intellectual Capital.

Lins, K. V., Servaes, H., \& Tamayo, A. (2017). Social capital, trust, and firm performance: The value of corporate social responsibility during the financial crisis. The Journal of Finance, 72(4), 1785-1824. https://doi.org/10.1111/jofi.12505

Louisa, F. (2016). The Role of Intellectual Capital in Achieving the Competitive Advantage of Economic Institutions in the Knowledge Economy: A Case Study of the Cement Company Ain Al-Toteh-Batna.

Ma, L., Zhai, X., Zhong, W., \& Zhang, Z. X. (2019). Deploying human capital for innovation: A study of multi-country manufacturing firms. International Journal of Production Economics, 208, 241-253. https://doi.org/10.1016/j.ijpe.2018.12.001

Madhavaram, S., \& Hunt, S. D. (2017). Customizing business-to-business (B2B) professional services: The role of intellectual capital and internal social capital. Journal of Business Research, 74, 38-46. https://doi.org/10.1016/j.jbusres.2017.01.007

Mahboob, A. H. and Abdul. R. (2016). Features and prospects of the future of the Saudi economy, London. https://doi.org/10.1108/jic-01-2016-0011

Makid, B. F. (2016). Psychological Empowerment and its Impact on Intellectual Capital - A Survey Study of the Views of the Tires of the Directorate of Gas and Electricity Distribution in Djelfa. Journal of Economics and Human Development.

Malkawi, F. H. (2015). Intellectual Construction: Its Concept, Levels and Maps. International Institute of Islamic Thought.

Manes Rossi, F., Citro, F., \& Bisogno, M. (2016). Intellectual capital in action: evidence from Italian local governments. Journal of Intellectual Capital, 17(4), 696-713.

Manuti, A., Impedovo, M. A., \& De Palma, P. D. (2017). Managing social and human capital in organizations: Communities of practices as strategic tools for individual and organizational development. Journal of Workplace Learning, 29(3), 217-234.

Massaro, M., Handley, K., Bagnoli, C., \& Dumay, J. (2016). Knowledge management in small and medium enterprises: a structured literature review. Journal of Knowledge Management, 20(2), 258-291. 
Massy, W. F., \& Archer, S. (2018). 6 Perspectives and advances on productivity measurement in higher education. Research Handbook on Quality, Performance and Accountability in Higher Education, 70.

Namada, J. M. (2018). Organizational learning and competitive advantage. In Handbook of Research on Knowledge Management for Contemporary Business Environments (pp. 86-104). IGI Global.

Nguyen, Q. (2016). The relationship between enterprise resource planning (ERP) implementation and intellectual capital under the moderating effect of organizational learning capability.

Osman, I., Maryam Jameelah, M. H., Noordin, F., \& Daud, N. (2016). An Analysis of Intellectual Capital and Turnover Intentions among Malaysian Employees in the Private Organisations. https://doi.org/10.1016/s2212-5671(16)00067-8

Roos, G. (2017). Knowledge management, intellectual capital, structural holes, economic complexity and national prosperity. Journal of Intellectual Capital, 18(4), 745-770. https://doi.org/10.1108/jic-07-2016-0072

Salafah, T. M. (2017). The role of intellectual capital in achieving the competitive advantage of banks in Sudan: a field study on a sample of commercial banks operating in Sudan. Sudan University of Science and Technology.

Sarhan, F. (2014). Total Quality Management: Recent Global Administrative Trends. Al-Sharif Mas Library, Cairo.

Schoenherr, T., Griffith, D. A., \& Chandra, A. (2014). Intangible capital, knowledge and new product development competence in supply chains: process, interaction and contingency effects among SMEs. International journal of production research, 52(16), 4916-4929. https://doi.org/10.1080/00207543.2014.894258

Shawadfi, M. G. (2017). The Role of the Business Climate in Developing Intellectual Capital: A Comparative Analytical Study in the Egyptian Business Environment. Qadisiyah Journal of Administrative and Economic Sciences, 2017.

Shuaib, M. A. M. (2014). Hospital Management: An Application Perspective.

Visnjic, I., Wiengarten, F., \& Neely, A. (2016). Only the brave: Product innovation, service business model innovation, and their impact on performance. Journal of Product Innovation Management, 33(1), 36-52. https://doi.org/10.1111/jpim.12254

Wang, Y. M., \& Wang, Y. C. (2016). Determinants of firms' knowledge management system implementation: An empirical study. Computers in Human behavior, 64, 829-842. https://doi.org/10.1016/j.chb.2016.07.055

Wang, Z., Wang, N., Cao, J., \& Ye, X. (2016). The impact of intellectual capital-knowledge management strategy fit on firm performance. Management Decision, 54(8), 1861-1885. https://doi.org/10.1108/md-06-2015-0231

Wei, L. Q., Liu, J., \& Herndon, N. C. (2011). SHRM and product innovation: Testing the moderating effects of organizational culture and structure in Chinese firms. The International Journal of Human Resource Management, 22(01), 19-33. https://doi.org/10.1080/ 09585192.2011.538965

Xu, J., \& Wang, B. (2019). Intellectual Capital Performance of the Textile Industry in Emerging Markets: A Comparison with China and South Korea. Sustainability, 11(8), 2354. https://doi.org/10.3390/su11082354

Yaseen, S. G., Dajani, D., \& Hasan, Y. (2016). The impact of intellectual capital on the competitive advantage: Applied study in Jordanian telecommunication companies. Computers in Human Behavior, 62, 168-175. https://doi.org/10.1016/j.chb.2016.03.075

Yassine, S. G. (2016). Electronic Management. Dar Al Yazuri Publishing, Amman, Jordan.

\section{Copyrights}

Copyright for this article is retained by the author(s), with first publication rights granted to the journal.

This is an open-access article distributed under the terms and conditions of the Creative Commons Attribution license (http://creativecommons.org/licenses/by/4.0/). 